\title{
Causes of death and predictors of childhood mortality in Rwanda: a matched case-control study using verbal social autopsy
}

Neil Gupta ${ }^{1,3,4^{*}}$ D, Lisa R. Hirschhorn ${ }^{2}$, Felix C. Rwabukwisi ${ }^{3}$, Peter Drobac ${ }^{1,3,4}$, Felix Sayinzoga ${ }^{5}$, Cathy Mugeni ${ }^{5}$, Fulgence Nkikabahizi ${ }^{5}$, Tatien Bucyana ${ }^{5}$, Hema Magge ${ }^{1,3}$, Daniel M. Kagabo ${ }^{3}$, Evrard Nahimana ${ }^{3}$, Dominique Rouleau ${ }^{3}$, Amelia VanderZanden $^{6}$, Megan Murray ${ }^{1,4}$ and Cheryl Amoroso ${ }^{3}$

\begin{abstract}
Background: Rwanda has dramatically reduced child mortality, but the causes and sociodemographic drivers for mortality are poorly understood.

Methods: We conducted a matched case-control study of all children who died before 5 years of age in eastern Rwanda between 1st March 2013 and 28th February 2014 to identify causes and risk factors for death. We identified deaths at the facility level and via a community health worker reporting system. We used verbal social autopsy to interview caregivers of deceased children and controls matched by area and age. We used InterVA4 to determine probable causes of death and cause-specific mortality fractions, and utilized conditional logistic regression to identify clinical, family, and household risk factors for death.
\end{abstract}

Results: We identified 618 deaths including 174 (28.2\%) in neonates and 444 (71.8\%) in non-neonates. The most commonly identified causes of death were pneumonia, birth asphyxia, and meningitis among neonates and malaria, acute respiratory infections, and HIV/AIDS-related death among non-neonates. Among neonates, 54 (31.0\%) deaths occurred at home and for non-neonates 242 (54.5\%) deaths occurred at home. Factors associated with neonatal death included home birth (aOR: 2.0; 95\% Cl: 1.4-2.8), multiple gestation (aOR: 2.1 ; 95\% Cl: 1.3-3.5), both parents deceased (aOR: $4.7 ; 95 \% \mathrm{Cl}: 1.5-15.3$ ), mothers non-use of family planning (aOR: 0.8; 95\% Cl: 0.6-1.0), lack of accompanying person (aOR: 1.6; 95\% Cl: 1.1-2.1), and a caregiver who assessed the medical services they received as moderate to poor (aOR: 1.5; 95\% Cl: 1.2-1.9). Factors associated with non-neonatal deaths included multiple gestation (aOR: 2.8; 95\% Cl: 1.7-4.8), lack of adequate vaccinations (aOR: 1.7; 95\% Cl: 1.2-2.3), household size (aOR: 1.2; 95\% Cl: 1.0-1.4), maternal education levels (aOR: 1.9; 95\% Cl: 1.2-3.1), mothers non-use of family planning (aOR: 1.6; 95\% Cl: 1.4-1.8), and lack of household electricity (aOR: 1.4; 95\% Cl: 1.0-1.8).

Conclusion: In the context of rapidly declining childhood mortality in Rwanda and increased access to health care, we found a large proportion of remaining deaths occur at home, with home deliveries still representing a significant risk factor for neonatal death. The major causes of death at a population level remain largely avoidable communicable diseases. Household characteristics associated with death included well-established socioeconomic and care-seeking risk factors.

\footnotetext{
* Correspondence: ngupta@pih.org

${ }^{1}$ Division of Global Health Equity, Brigham \& Women's Hospital, Boston, USA

${ }^{3}$ Partners In Health/Inshuti Mu Buzima, Rwinkwavu, Rwanda

Full list of author information is available at the end of the article
}

(c) The Author(s). 2018 Open Access This article is distributed under the terms of the Creative Commons Attribution 4.0 International License (http://creativecommons.org/licenses/by/4.0/), which permits unrestricted use, distribution, and reproduction in any medium, provided you give appropriate credit to the original author(s) and the source, provide a link to the Creative Commons license, and indicate if changes were made. The Creative Commons Public Domain Dedication waiver (http://creativecommons.org/publicdomain/zero/1.0/) applies to the data made available in this article, unless otherwise stated. 


\section{Background}

The Millennium Development Goal \#4 to reduce child mortality by two thirds by the end of 2015 resulted in an unprecedented focus on child health and a $52 \%$ reduction in sub-Saharan Africa between 1990 to 2015, from 179 to 86 deaths per 1000 live births [1]. Despite global achievements, only one-third of the priority countries in sub-Saharan Africa reached their child mortality target. This achievement gap translated into an estimated 2.9 million child deaths in 2015 in sub-Saharan Africa, of which two-thirds were likely from preventable causes [2] and $45 \%$ occurred in the neonatal period. Poverty and maternal education continue to play a key role in determining child mortality, and severe challenges remain in health care financing, human resources, service utilization, and information systems [3-5].

Rwanda, a country of 11.4 million people in the Great Lakes region of Africa, has made dramatic improvements in child mortality, moving from 37 neonatal and 152 under-5 deaths per 1000 live births in 2005 to 20 and 50 per 1000 live births, respectively, in 2015 [6]. This reduction in child mortality occurred in the context of multiple cross-sectional national and decentralized interventions designed to increase access to care, improve health resources, and strengthen the provision of effective care. These included the national introduction of a community health insurance program, high coverage for vaccination and vitamin A supplementation, implementation of community-based Integrated Management of Childhood Illness (IMCI), provision of insecticide treated nets, near elimination of mother to child HIV infections, increase in facility-based deliveries, and mobile phone reporting/support for emergency pre- and post-natal care [7-9].

Despite these efforts, child mortality in Rwanda, as in other countries in resource-poor regions of sub-Saharan Africa, varies widely across the country. Child mortality remains higher in the Eastern Province of Rwanda, which has the highest infant (51 deaths per 1000 live births) and under-5 mortality (86 deaths per 1000 live births) as compared to other provinces [6]. Nationally, under- 5 mortality is largely associated with poverty (84/ 1000 live births in the lowest wealth quintile vs. 40/1000 live births in the highest quintile), maternal education $(89 / 1000$ live births in mothers with no education vs. $43 / 1000$ for women with secondary education or higher), and residence (70/1000 in rural areas vs. 51/1000 in urban areas) [7]. However, the immediate causes and sociodemographic drivers for mortality particularly among those in the lowest wealth quintiles are poorly understood.

In order to fill this knowledge gap, we implemented a verbal social autopsy (VSA). In addition to the biologic factors identified in traditional verbal autopsy interviews,
VSA allows for in-depth understanding of social, behavioral, and systems determinants of childhood death, as well as the caregiver's experience and perspectives, thereby identifying potential modifiable targets in the home, community, and health system [10-12]. We conducted a matched case-control study utilizing an enhanced VSA interview tool to determine probable cause of and predictive factors for childhood deaths in an area of high rates of childhood mortality in Rwanda.

\section{Methods \\ Study setting}

This study was conducted in two rural Eastern Province hospital catchment areas covering approximately 529,000 individuals. In this intervention area, the Ministry of Health $(\mathrm{MOH})$ facilities have been financially and technically supported by the non-governmental organization Partners In Health/Inshuti Mu Buzima (PIH/IMB) since 2005.

In Rwanda, the health system includes three main levels: community, health center, and district hospital. Community health workers (CHWs) provide household level health education, case finding for acute and chronic illness, community IMCI (including diagnosis and treatment of pneumonia, diarrhea, and malaria), female contraception, and linkage to health facilities for prenatal care, deliveries, and other medical services [13]. Each of the 23 health centers serve a catchment area of approximately 20,000-30,000 people and are staffed by general nurses who provide basic diagnostics, outpatient acute services, family planning, prenatal care, and routine deliveries. The average walking distance from households to the nearest health facility is estimated at just over an hour in Kayonza and over an hour and a half in Kirehe [14]. Reflecting national standards, district hospitals in Eastern Province are staffed by general practitioners and nurses who provide secondary care for advanced or inpatient care for patients referred from health centers, including comprehensive obstetric emergencies requiring cesarean section, neonatal care, and inpatient treatment for severe childhood illness and severe malnutrition.

\section{Study design and data collection}

We conducted a matched case-control study of all children who died before 5 years of age in the study area between 1st March 2013 and 28th February 2014. We identified deaths using multiple sources including facility registers, community health worker reports, monthly review of $\mathrm{CHW}$-held community death records, and a database from a mobile phone-based reporting system, the Monitoring of Vital Events using Information Technology (MoVe-IT), which was introduced in these two districts in 2012 to improve vital events reporting [15]. 
After confirming childhood deaths with local CHWs, we conducted interviews with caregivers of the deceased child in their households. Trained data collectors approached caregivers between three weeks to one year following the child's death. Each case was matched to two controls selected from the nearest households with a child in a comparable age group (for neonates, children aged 1-30 days; for infants, children aged 31 days up to 1 year; and for children older than one year, matched to those between 1 and 5 years) to the deceased child. Neonatal cases without an available control under 30 days of age were matched with infants up to 180 days of age. Prior to the VSA, interviewers asked families of neonatal deaths additional questions in order to screen out potential cases of stillbirth. We obtained written informed consent from the caregivers of the deceased children and those selected as controls. The current caregiver of the child was not necessarily the biological mother if the biological mother was not available or was deceased. Using a questionnaire based on the 2012 World Health Organization verbal autopsy (VA) tool [16] supplemented with questions from the Rwanda MOH's Under-5 Death Audit Tool and the 2010 Rwanda Demographic and Health Survey, we obtained information on the case or control child's demographic characteristics, information on the child's birth, illness, care seeking, and the family's perceptions of care.

\section{Analysis}

We used InterVA4 [17] to determine probable causes of death and cause-specific mortality fractions (CSMF) for each cause of death. The InterVA algorithm uses a range of health indicators taken from interviews as input and applies Bayes' Theorem to determine the likeliest cause of death. The CSMF is an output from the algorithm and can be interpreted as the total number of deaths attributable to a specific cause. Prevalence of HIV and malaria were entered as "high" in the InterVA model, based on national level facility reporting indicating an estimate of greater than one in 100 deaths due to each of these diseases [18]. We estimated odds ratios for a range of child, caretaker, household, and care-seeking characteristics using conditional logistic regression. We retained variables with $p$-value less than or equal to 0.2 significance level in the univariate analyses in a multivariate model. We performed multiple imputations to infer values of missing data, which were considered missing completely at random. We used a bidirectional elimination stepwise method, which uses both forward selection and backward elimination in succession to determine optimal variables, to arrive at a final model in which the remaining variables were significant at the $\alpha$ $=0.05$ level. Risk factors with potential collinearity were not included in multivariate analysis. We analyzed deaths in neonates (day of life 0 to 28) and non-neonates (day of life 29 to 5 years) separately. We used Global Burden of Disease level 1 categories [19] to organize causes of death by communicable, maternal, neonatal, and nutritional disorders (Group 1), non-communicable diseases (Group 2), and injuries (Group 3).

\section{Ethical approval}

This study was approved by the Rwanda National Ethics Committee and Partners Institutional Review Board under the Population Health Implementation and Training program, a partnership between PIH/IMB, the University of Rwanda, and the Rwanda MOH. All caregivers who participated provided informed consent and were informed that they were able to discontinue participation at any time during the interview.

\section{Results}

\section{Mortality results}

Overall, 618 deaths were identified during the study period: $174(28.2 \%)$ in neonates and $444(71.8 \%)$ in non-neonates. For neonates, the median age of death was 2 days (interquartile range [IQR]: $0-7$ ); $49.4 \%$ occurred in the first $48 \mathrm{~h}$ and $75.9 \%$ in the first week of life (Table 1). Nearly one-third (32.8\%) of neonates did not visit a hospital or health center during the course of illness; $39.9 \%$ of neonates received no treatment for the illness that preceded their death. Among those that did seek care prior to the death, $16.7 \%$ were first evaluated by a community health worker; more than half were first evaluated either at a health center $(43.7 \%)$ or district hospital (12.6\%). Of the 174 neonatal deaths, data regarding discharge were present for 127 neonates. Of those, 97 (76.4\%) were never discharged from the hospital following birth. Sixteen percent of the neonates were born through non-facility delivery. One hundred and eight $(62.1 \%)$ of the neonatal deaths were in health facilities and $54(31.0 \%)$ were at home. The majority (CSMF 66.7\%) of identified causes of neonatal death were from Group 1 communicable or neonatal causes including pneumonia and birth asphyxia. The CSMF for deaths from Group 2 (non-communicable diseases) was $2.0 \%$; $31.3 \%$ could not be assigned a specific cause (Table 2).

Among non-neonates, just under one-third (32.7\%) of cases did not visit a hospital or health center during the course of illness; $29.5 \%$ received no treatment for the illness that preceded their death (Table 1). Among those that did seek care prior to the death, $36.9 \%$ were first evaluated by a community health worker; about one in three were first evaluated either at a health center (29.9\%) or district hospital (2.0\%). The median age of death was 515 days (IQR: 192-998); 122 deaths (27.5\%) were in health facilities and 242 (54.5\%) were at home. 
Table 1 Characteristics of under-5 deaths

\begin{tabular}{|c|c|c|c|}
\hline & $\begin{array}{l}\text { All U5 }(N=618) \\
N(\%)\end{array}$ & $\begin{array}{l}\text { Neonate }(N=174) \\
N(\%)\end{array}$ & $\begin{array}{l}\text { Non-Neonate }(N=444) \\
N(\%)\end{array}$ \\
\hline \multicolumn{4}{|l|}{$\operatorname{Sex}(n=618)$} \\
\hline Male & $347(56.2)$ & $104(59.8)$ & $243(54.7)$ \\
\hline Female & $271(43.9)$ & $70(40.2)$ & $201(45.3)$ \\
\hline \multicolumn{4}{|l|}{ Timing of neonatal death $(n=170)$} \\
\hline Died within $24 \mathrm{~h}$ of birth & - & 69 (40.6) & - \\
\hline Died between 24 and $48 \mathrm{~h}$ of life & - & $15(8.8)$ & - \\
\hline Died between $48 \mathrm{~h}$ and 1 week of life & - & $45(26.5)$ & - \\
\hline Died between 1 week and 28 days of life & - & $41(24.1)$ & - \\
\hline \multicolumn{4}{|l|}{ First type of care sought $(n=618)$} \\
\hline Traditional healer & $50(8.1)$ & $8(4.6)$ & $42(9.4)$ \\
\hline Community health worker & $193(31.2)$ & $29(16.7)$ & $164(36.9)$ \\
\hline Health center & $209(33.8)$ & $76(43.7)$ & $133(29.9)$ \\
\hline District hospital & $31(5.0)$ & $22(12.6)$ & $9(2.0)$ \\
\hline Private pharmacy & $5(1.0)$ & $0(0.0)$ & $5(1.1)$ \\
\hline Other & $19(3.1)$ & $4(2.3)$ & $15(3.4)$ \\
\hline Unknown & $32(5.2)$ & $12(6.9)$ & $20(4.5)$ \\
\hline No care sought & $79(12.8)$ & $23(13.2)$ & $56(12.6)$ \\
\hline \multicolumn{4}{|c|}{ Attended health facility (hospital or health center) during illness ( $n=616$ ) } \\
\hline No & $202(32.7)$ & $57(32.8)$ & $145(32.7)$ \\
\hline Yes & $416(67.3)$ & $117(67.2)$ & $299(67.3)$ \\
\hline \multicolumn{4}{|c|}{ Received any treatment at a health facility for the illness that led to death $(n=608)$} \\
\hline No & $197(32.4)$ & $67(39.9)$ & $130(29.5)$ \\
\hline Yes & $411(67.6)$ & $101(60.1)$ & $310(70.5)$ \\
\hline \multicolumn{4}{|l|}{ Place of death $(n=618)$} \\
\hline Hospital & $156(25.2)$ & $80(46.0)$ & $76(17.1)$ \\
\hline Health center & $74(12.0)$ & $28(16.1)$ & $46(10.4)$ \\
\hline Home & $296(47.9)$ & $54(31.0)$ & $242(54.5)$ \\
\hline Other & $91(14.7)$ & $12(6.9)$ & 79 (17.8) \\
\hline Unknown & $1(0.2)$ & $0(0.0)$ & $1(0.2)$ \\
\hline \multicolumn{4}{|c|}{ Discharged from health facility following birth $(n=127)$} \\
\hline No (died in health facility) & - & $97(76.4)$ & - \\
\hline Yes & - & $30(23.6)$ & - \\
\hline
\end{tabular}

More than three-quarters of these deaths (CSMF 82.9\%) were classified as due to Group 1 diseases including malaria, acute respiratory infections, HIV/AIDS related deaths, and diarrheal diseases (Table 2). Other avoidable causes included Group 2 diseases (CSMF 3.9\%) and Group 3 causes (injuries) (CSMF 3.7\%); 9.5\% deaths could not be assigned a specific cause.

\section{Risk factors for death among neonates}

In the univariate analysis, we identified the following as risk factors for neonatal death: female child (OR: 0.8; 95\% CI: 0.7-1.0), home birth (OR: 1.8; 95\% CI: 1.3-2.7), multiple gestation birth (OR: 1.9; 95\% CI: 1.1-3.3), both parents deceased (OR: 3.8; 95\% CI: 1.2-12.7), non-use of family planning methods (OR: 0.8 ; 95\% CI: 0.6-1.0), and barriers to care including lack of accompaniment to a health facility (OR: 1.5; 95\% CI: 1.1-2.1) and caregiver assessment of services received as moderate to poor (OR: 1.5; 95\% CI: 1.1-2.0) (Table 3). In multivariate analysis, neonates who died were more likely than controls to have been born at home (aOR: $2.0 ; 95 \% \mathrm{CI}: 1.4-2.8$ ), born as part of a multiple gestation (aOR: 2.1 ; 95\% CI: 1.3-3.5), and to have both parents deceased (aOR: 4.7; 95\% CI: 1.5-15.3). They were less likely to have a 
Table 2 Cause-specific mortality fractions for neonates (day of life 0 to 28) and non-neonates (day of life 29 to 5 years)

\begin{tabular}{|c|c|c|c|c|c|c|}
\hline \multirow[t]{2}{*}{ Age group } & \multicolumn{2}{|l|}{$\begin{array}{l}\text { GBD Group } 1 \text { (Communicable, maternal, } \\
\text { neonatal, and nutritional disorders) }\end{array}$} & \multicolumn{2}{|c|}{$\begin{array}{l}\text { GBD Group } 2 \text { (Non-communicable } \\
\text { diseases) }\end{array}$} & \multicolumn{2}{|l|}{ GBD Group 3 (Injuries) } \\
\hline & Cause of death & CSMF & Cause of death & CSMF & Cause of death & CSMF \\
\hline \multirow[t]{8}{*}{ Neonates } & Neonatal pneumonia & 26.5 & Congenital malformation & 1.0 & & \\
\hline & Birth asphyxia & 11.3 & Epilepsy & 0.6 & & \\
\hline & Other and unspecified neonatal COD & 8.5 & $\begin{array}{l}\text { Other and unspecified cardiac } \\
\text { disease }\end{array}$ & 0.4 & & \\
\hline & Meningitis and encephalitis & 7.9 & & & & \\
\hline & Prematurity & 6.4 & & & & \\
\hline & Neonatal sepsis & 5.6 & & & & \\
\hline & Acute abdomen ${ }^{a}$ & 0.5 & & & & \\
\hline & TOTAL & 66.7 & TOTAL & 2.0 & TOTAL & - \\
\hline \multirow[t]{9}{*}{$\begin{array}{l}\text { Non- } \\
\text { neonates }\end{array}$} & Malaria & 34.7 & Epilepsy & 2.3 & $\begin{array}{l}\text { Accidental drowning and } \\
\text { submersion }\end{array}$ & 1.3 \\
\hline & $\begin{array}{l}\text { Acute resp. infections, including } \\
\text { pneumonia }\end{array}$ & 19.7 & Congenital malformation & 0.9 & Road traffic accident & 0.7 \\
\hline & HIV/AIDS-related death & 12.0 & Asthma & 0.7 & $\begin{array}{l}\text { Other and unspecified } \\
\text { external COD }\end{array}$ & 0.6 \\
\hline & Acute abdomen $^{a}$ & 7.6 & & & Other transport accident & 0.6 \\
\hline & Diarrheal diseases & 5.9 & & & Assault & 0.5 \\
\hline & Meningitis and encephalitis & 1.2 & & & & \\
\hline & Other and unspecified infect disease & 0.9 & & & & \\
\hline & Severe malnutrition & 0.9 & & & & \\
\hline & TOTAL & 82.9 & TOTAL & 3.9 & TOTAL & 3.7 \\
\hline
\end{tabular}

$31.3 \%$ of neonatal deaths and $9.5 \%$ of non-neonatal deaths identified as "indeterminate"

$C O D$ cause of death, CSMF Cause-specific mortality fraction, GBD Global Burden of Disease

${ }^{\mathrm{a}}$ May have mixed etiologies

mother who reported using family planning methods (aOR: 0.8; 95\% CI: 0.6-1.0), and were more likely to have a caregiver who reported that not having a family member available to accompany them to a health facility was a barrier to care (aOR: 1.6; 95\% CI: 1.1-2.1), and who assessed the medical services they received as moderate to poor (aOR: 1.5 ; 95\% CI: $1.2-1.9$ ).

\section{Non-neonates case-control results}

In the univariate analyses, children who died were more likely than controls to have been a part of a multiple gestation birth (OR: 2.8; 95\% CI: 1.7-4.7), not to have received adequate vaccinations (OR: 1.7 ; $95 \%$ CI: $1.2-$ 2.3), and to come from a larger household (OR: 1.2; 95\% CI: 1.0-1.4). Mothers of non-neonatal cases were more likely than age-matched controls to have primary education or less (OR: 1.9; 95\% CI: 1.2-3.0) and not use family planning methods (OR: 1.6; 95\% CI: 1.4-1.8). Caregivers were less likely to have health insurance (OR: 0.9; $95 \%$ CI: $0.7-1.0)$ and more likely to report no household electricity (OR: 1.4; 95\% CI: 1.0-1.8) as well as financial barriers to care (OR: 1.1; 95\% CI: 1.0-1.3) (Table 4). In the multivariate model, children who died were more likely than controls to have been born as part of a multiple gestation (aOR: 2.8; 95\% CI: 1.7-4.8), to not have received all scheduled vaccinations (aOR: 1.7; 95\% CI: 1.2-2.3), and to come from a large household (aOR: 1.2; $95 \%$ CI: $1.0-1.4)$. Caretakers were also more likely to report lower maternal education levels (aOR: 1.9; 95\% CI: 1.2-3.1), mothers not using family planning (aOR: 1.6; 95\% CI: 1.4-1.8), and electricity lacking in the household (aOR: 1.4; 95\% CI: 1.0-1.8). The variable "mother health insurance" was not included in the multivariate analysis due to potential collinearity with "caretaker reported financial barrier to care".

\section{Discussion}

In the context of rapidly declining childhood mortality in Rwanda and increased access to and utilization of formal health care, we found a large proportion of remaining deaths occur at home, and home deliveries still representing a significant risk factor for neonatal death. The major causes of death at a population level remain largely avoidable communicable diseases. Household characteristics associated with death included well-established socioeconomic and care-seeking risk factors. To our knowledge, this is the first study to explore the causes of death in Rwanda using 
Table 3 Risk factors for neonatal death as compared to matched controls

\begin{tabular}{|c|c|c|c|c|c|c|c|c|}
\hline \multicolumn{5}{|l|}{ Univariate Analysis } & \multicolumn{4}{|c|}{ Multivariate Analysis } \\
\hline \multirow{2}{*}{$\begin{array}{l}\text { Child, Caretaker, or Household Characteristic } \\
\text { Female child }\end{array}$} & \multirow{2}{*}{$\begin{array}{l}\text { Odds Ratio } \\
0.8\end{array}$} & \multicolumn{2}{|c|}{$\begin{array}{l}\text { 95\% Confidence } \\
\text { Interval }\end{array}$} & \multirow{2}{*}{$\begin{array}{l}p \text {-value } \\
0.091\end{array}$} & \multirow{2}{*}{$\begin{array}{l}\begin{array}{l}\text { Odds } \\
\text { ratio }\end{array} \\
0.8\end{array}$} & \multicolumn{2}{|c|}{$\begin{array}{l}\text { 95\% Confidence } \\
\text { Interval }\end{array}$} & \multirow{2}{*}{$\begin{array}{c}p \text {-value } \\
0.084\end{array}$} \\
\hline & & 0.7 & 1.0 & & & 0.7 & 1.0 & \\
\hline Mother with primary education or less & 0.9 & 0.6 & 1.4 & 0.655 & - & - & - & - \\
\hline Mother age $\leq 18$ & 1.4 & 0.5 & 3.9 & 0.506 & - & - & - & - \\
\hline Mother age $>35$ & 0.8 & 0.4 & 1.6 & 0.564 & - & - & - & - \\
\hline Mother with health insurance & 0.8 & 0.6 & 1.2 & 0.340 & - & - & - & - \\
\hline Both parents deceased & 3.8 & 1.2 & 12.7 & 0.027 & 4.7 & 1.5 & 15.3 & 0.01 \\
\hline Household size $\geq 5$ & 1.2 & 0.9 & 1.5 & 0.206 & - & - & - & - \\
\hline No electricity in the house & 0.9 & 0.5 & 1.6 & 0.744 & - & - & - & - \\
\hline Natural/rudimentary walls in the house & 0.8 & 0.6 & 1.2 & 0.310 & - & - & - & - \\
\hline No mosquito nets in the house & 1.0 & 0.7 & 1.5 & 0.962 & - & - & - & - \\
\hline Mother not using family planning & 0.8 & 0.6 & 1.0 & 0.041 & 0.8 & 0.6 & 1.0 & 0.042 \\
\hline Home delivery & 1.8 & 1.3 & 2.7 & 0.002 & 2.0 & 1.4 & 2.8 & 0.000 \\
\hline Multiple gestation delivery & 1.9 & 1.1 & 3.3 & 0.016 & 2.1 & 1.3 & 3.5 & 0.005 \\
\hline Mother with $\leq 1$ antenatal care visit & 1.3 & 0.9 & 1.8 & 0.233 & - & - & - & - \\
\hline Caretaker reported financial barrier to care & 1.1 & 0.9 & 1.5 & 0.372 & - & - & - & - \\
\hline Caretaker reported seeking permission as a barrier to care & 1.0 & 0.5 & 1.8 & 0.991 & - & - & - & - \\
\hline Caretaker reported distance to health facility as a barrier to care & 1.0 & 0.7 & 1.4 & 0.946 & - & - & - & - \\
\hline Caretaker reported not having an accompanying person as a barrier to care & 1.5 & 1.1 & 2.1 & 0.015 & 1.6 & 1.1 & 2.1 & 0.007 \\
\hline Caretaker reported a poor to moderate perception of health facility services & 1.5 & 1.1 & 2.0 & 0.004 & 1.5 & 1.2 & 1.9 & 0.002 \\
\hline
\end{tabular}

Table 4 Risk factors for non-neonatal death as compared to matched controls

\begin{tabular}{|c|c|c|c|c|c|c|c|c|}
\hline \multicolumn{5}{|l|}{ Univariate Analysis } & \multicolumn{4}{|c|}{ Multivariate Analysis } \\
\hline \multirow{2}{*}{$\begin{array}{l}\text { Child, Caretaker, or Household Characteristic } \\
\text { Female child }\end{array}$} & \multirow{2}{*}{$\begin{array}{l}\text { Odds Ratio } \\
0.9\end{array}$} & \multicolumn{2}{|c|}{$\begin{array}{l}\text { 95\% Confidence } \\
\text { Interval }\end{array}$} & \multirow{2}{*}{$\begin{array}{l}p \text {-value } \\
0.241\end{array}$} & \multirow{2}{*}{$\begin{array}{l}\begin{array}{l}\text { Odds } \\
\text { ratio }\end{array} \\
-\end{array}$} & \multicolumn{2}{|c|}{$\begin{array}{l}\text { 95\% Confidence } \\
\text { Interval }\end{array}$} & \multirow{2}{*}{$\frac{p \text {-value }}{-}$} \\
\hline & & 0.8 & 1.1 & & & - & - & \\
\hline Mother with primary education or less & 1.9 & 1.2 & 3.0 & 0.006 & 1.9 & 1.2 & 3.1 & 0.005 \\
\hline Mother age $\leq 18$ & 0.8 & 0.4 & 1.7 & 0.554 & - & - & - & - \\
\hline Mother age $>35$ & 1.3 & 0.8 & 2.0 & 0.235 & - & - & - & - \\
\hline Mother with health insurance & 0.9 & 0.7 & 1.0 & 0.111 & - & - & - & - \\
\hline Both parents deceased & 1.2 & 0.7 & 1.8 & 0.490 & - & - & - & - \\
\hline Household size $\geq 5$ & 1.2 & 1.0 & 1.4 & 0.029 & 1.2 & 1.0 & 1.4 & 0.037 \\
\hline No electricity in the house & 1.4 & 1.0 & 1.8 & 0.052 & 1.4 & 1.0 & 1.8 & 0.041 \\
\hline Natural/rudimentary walls in the house & 0.9 & 0.8 & 1.2 & 0.566 & - & - & - & - \\
\hline No mosquito nets in the house & 0.9 & 0.7 & 1.2 & 0.475 & - & - & - & - \\
\hline Mother not using family planning & 1.6 & 1.4 & 1.8 & $<.0001$ & 1.6 & 1.4 & 1.8 & $<.0001$ \\
\hline Multiple gestation delivery & 2.8 & 1.7 & 4.7 & $<.0001$ & 2.8 & 1.7 & 4.8 & $<.0001$ \\
\hline Child not adequately vaccinated & 1.7 & 1.2 & 2.3 & 0.003 & 1.7 & 1.2 & 2.3 & 0.003 \\
\hline Caretaker reported financial barrier to care & 1.1 & 1.0 & 1.3 & 0.155 & 1.1 & 0.8 & 1.3 & 0.109 \\
\hline Caretaker reported seeking permission as a barrier to care & 0.9 & 0.7 & 1.3 & 0.714 & - & - & - & - \\
\hline Caretaker reported distance to health facility as a barrier to care & 1.0 & 0.8 & 1.1 & 0.649 & - & - & - & - \\
\hline Caretaker reported not having an accompanying person as a barrier to care & 1.1 & 0.9 & 1.3 & 0.482 & - & - & - & - \\
\hline Caretaker reported a poor to moderate perception of health facility services & 1.0 & 0.9 & 1.2 & 0.962 & - & - & - & - \\
\hline
\end{tabular}


household-level VSA, including a case-control design to also explore the association of socio-demographic and access factors with the risk of neonatal and childhood deaths.

Although the proportion of neonatal deaths in the first week of life in this cohort $(75.9 \%)$ was similar to previous reports based on vital registration data, $[20,21]$ our results showed a lower proportion of neonatal asphyxia and prematurity-related deaths than both regional estimates and previous results in Rwanda [22, 23]. These findings may reflect the contribution of programs in these districts targeting survival of premature and full-term infants through improved neonatal resuscitation techniques and immediate newborn care, including introduction of continuous positive airway pressure at the hospital level [24]. For non-neonatal deaths, the causes of death estimated from our study continue to attribute a high overall cause of death to preventable communicable disease, driven in large part by malaria, pneumonia, and diarrheal diseases. Despite national malaria control efforts, there are higher rates of malaria incidence in the Eastern region of Rwanda [25]; in addition, the country experienced an upsurge in cases of malaria during the time of data collection, attributed to climate changes, pyrethroid resistance, sub-standard insecticide-treated bednets, and inconsistent application of indoor residual spraying $[18,26]$. The relative proportion of deaths attributable to pneumonia was consistent with both regional and historical rates [21, 23]. In contrast, a lower proportion of deaths were attributable to diarrhea than previously reported [23], likely due in part to the expansion of community IMCI and efforts to improve quality of facility-based IMCI [27].

In multivariate analysis, home birth was a significant risk for neonatal mortality, and $16 \%$ of cases of neonatal death identified in this study occurred in neonates with nonfacilitydelivery. This supports findings among cohorts in Uganda [28] and Indonesia [29] which showed substantially elevated mortality risk associated with birth at home. This increased risk may be due to the lack of immediate access to emergency clinical obstetric or neonatal care among home births without skilled attendants as well as low utilization of post-partum care and services [30]. Orphanhood, or both parents deceased, was also associated with higher odds of death among neonates, and has been reported elsewhere to be a major risk factor for childhood mortality [31]. A previous study in Tanzania found that children whose mothers died during the early maternal period had a $50 \%$ chance of surviving to one year of age compared to a $94 \%$ probability among children with living mothers [32].

Several established risk factors were confirmed in our research, including multiple gestation birth [31, 33], lower maternal education [4, 34, 35], larger household size $[34,36]$, absence of family planning use [37, 38], and incomplete vaccination [39]. Lack of household electricity was another significant factor for non-neonatal deaths, which may be directly associated with greater indoor air pollution from other energy sources [40], an increase in injuries and accidents related to solid fuel use [41], or be a surrogate for other household vulnerabilities. Household electricity may also be associated with greater family or community resources that provide a protective effect on under- 5 health outcomes $[42,43]$.

Self-reported barriers to accessing care were significantly associated with deaths in the neonatal age group. Lack of a family member or other person to accompany a caregiver to the health facility was independently associated with neonatal death, which likely resulted in delays in care seeking and may also be reflected in the higher risk of death associated with home birth.

Lack of insurance was not significantly associated with deaths in either age category in the analysis. Given the high rates of insurance coverage for mothers in cases and controls, our study may have lacked sufficient power to detect significant risk factors for death. Whereas a community-based health insurance scheme has been associated with increased utilization of child services at health facilities in Rwanda [44], user fees still exist in the form of co-payment, which may to some degree still limit access to care [45], findings supported from initial qualitative analysis of the VSA interviews [46]. Inadequate utilization of family planning, which was independently associated with childhood deaths in this study, may reflect lower health seeking-behaviors or poorer access to care by caretakers of children who died compared to caretakers of the control children.

Our study had a number of limitations. While the updated 2012 WHO VA tool and InterVA4 algorithm in use are confirmed to have high reliability compared to other vital case reporting standards $[47,48]$, the accuracy of the identified cause of death from the algorithm in this country and context is unknown, especially for neonates, where a large proportion of deaths were categorized as indeterminate cause, or for particular conditions, such as malnutrition, which may go under-detected using this methodology. Additionally, VSA relies on caregiver recall of events surrounding the death, which introduces issues related to caregiver memory of the events and responder bias, particularly given the sensitivity of an event as significant as the death of a child. In particular, this bias may influence assessment of barriers to care. The InterVA4 algorithm requires prevalence assumptions for the rate of deaths attributed to HIV in the background population. According to national facility-based reporting, $1 \%$ of childhood deaths and $6 \%$ of all deaths in 2014 were associated with HIV/ AIDS, though this may have overestimated the 
proportion of overall childhood deaths related to HIV/ AIDS, where a rapidly declining HIV vertical transmission rate and improving diagnostics and access to treatment have dramatically reduced HIV/AIDS-related death in the pediatric population in Rwanda [49]. Additionally, while efforts were made to collect data from multiple new and existing data sources, some deaths may have been missed, particularly deaths initially thought to be stillbirths in both facility and community settings, thereby potentially underestimating the proportion of neonatal deaths. Childhood vaccination coverage was not corrected for survival, and therefore it is possible that the relationship between complete vaccination coverage and childhood mortality may have been overestimated due to the additional time that passed between the death date of the case and the interview date for the control, during which the control may have received additional vaccinations. Despite standardized procedures to collect interview data, data is missing for several variables; however, we believe these data are missing at random, and do not bias our findings. Finally, while we had caregiver report of perceived quality, we do not know the technical quality of care provided and the relative contribution to amenable deaths.

\section{Conclusion}

Despite significant health system improvements and rapid declines in childhood mortality in Rwanda, a large proportion of child deaths in this study occurred at home. While there was a high proportion of facilitybased deaths for neonates, home deliveries still represent a major risk factor for neonatal death. Significant financial and care-seeking barriers remain with a high proportion of deaths occurring outside of the health system for non-neonates, which present clear targets for focused interventions at both the community and health facility levels. Despite overall gains in childhood mortality, well informed policies, guidelines, and system improvements targeting key risk factors identified in this study could accelerate gains for neonatal and childhood survival in rural Rwanda and similar contexts across sub-Saharan Africa.

\section{Abbreviations \\ CHW: Community health worker; CSMF: Cause-specific mortality fraction; GBD: Global Burden of Disease; IMB: Inshuti Mu Buzima; IMCI: Integrated Management of Childhood IIIness; $\mathrm{MOH}$ : Ministry of Health; MoVe- IT: Monitoring of Vital Events using Information Technology; PIH: Partners In Health; VA: Verbal autopsy; VSA: Verbal social autopsy; WHO: World Health Organization}

\section{Acknowledgements}

The authors would like to acknowledge the data collectors, study staff, and community health workers for their dedication to the families involved in this study. We acknowledge the contributions of Hari lyer, Catherine Kirk, Kenji Matsumoto, and Joshua Rutsohn for data analysis and manuscript preparation, and Dr. Patient Ngamije for hospital leadership.

\section{Funding}

This study was supported by funds from the African Health Initiative of the Doris Duke Charitable Foundation.

\section{Availability of data and materials}

The datasets generated and/or analyzed during the current study are available from the corresponding author upon reasonable request and following established procedures by the Partners In Health Research Department.

\section{Authors' contributions \\ $\mathrm{LRH}, \mathrm{MM}, \mathrm{CM}, \mathrm{TB}$, and CA contributed to study conception and design. DMK, $\mathrm{DR}$, and $\mathrm{CA}$ conducted data collection. NG, LRH, DR, MM, and CA participated in data analysis. NG, LRH, FCR, PD, FS, CM, FN, TB, HM, DMK, EM, $\mathrm{DR}, \mathrm{AV}, \mathrm{MM}$, and $\mathrm{CA}$ assisted in data interpretation. $\mathrm{NG}, \mathrm{LRH}, \mathrm{AV}$, and $\mathrm{CA}$ participated in drafting the manuscript. FCR, PD, FS, CM, FN, TB, HM, DMK, $\mathrm{EN}, \mathrm{DR}$, and MM critically reviewed the manuscript. All authors had a role in writing the manuscript and read and approved the final manuscript.}

\section{Ethics approval and consent to participate}

This study was approved by the Rwanda National Ethics Committee and Partners Institutional Review Board under the Population Health Implementation and Training program, a partnership between $\mathrm{PIH} / \mathrm{IMB}$, the University Rwanda, and the Rwanda $\mathrm{MOH}$. All caregivers who participated provided written informed consent and were informed that they were able to discontinue participation at any time during the interview.

Consent for publication

Not applicable.

\section{Competing interests}

The authors declare they have no competing interests.

\section{Publisher's Note}

Springer Nature remains neutral with regard to jurisdictional claims in published maps and institutional affiliations.

\section{Author details \\ ${ }^{1}$ Division of Global Health Equity, Brigham \& Women's Hospital, Boston, USA. ${ }^{2}$ Northwestern University Feinberg School of Medicine, Chicago, USA. \\ ${ }^{3}$ Partners In Health/Inshuti Mu Buzima, Rwinkwavu, Rwanda. ${ }^{4}$ Department of Global Health and Social Medicine, Harvard Medical School, Boston, USA. ${ }^{5}$ Ministry of Health of Rwanda, Kigali, Rwanda. ${ }^{6}$ Ariadne Labs, Boston, USA.}

Received: 5 January 2018 Accepted: 29 November 2018

Published online: 17 December 2018

\section{References}

1. The Millenium Development Goals Report 2015. United Nations; 2015

2. You D, Hug L, Ejdemyr S, Idele P, Hogan D, et al. Global, regional, and national levels and trends in under-5 mortality between 1990 and 2015, with scenario-based projections to 2030: a systematic analysis by the UN Inter-agency Group for Child Mortality Estimation. Lancet 2015;386:2275-86.

3. Black RE, Victora CG, Walker SP, Bhutta ZA, Christian P, et al. Maternal and child undernutrition and overweight in low-income and middle-income countries. Lancet. 2013;382(9890):427-51.

4. Gakidou E, Cowling K, Lozano R, Murray CJ. Increased educational attainment and its effect on child mortality in 175 countries between 1970 and 2009: a systematic analysis. Lancet. 2010;376(9745):959-74.

5. Requejo JH, Bryce J, Barros AJ, Berman P, Bhutta Z, et al. Countdown to 2015 and beyond: fulfilling the health agenda for women and children. Lancet. 2015;385(9966):466-76.

6. National Institute of Statistics of Rwanda. Rwanda Ministry of Health, and ICF international. In: Rwanda demographic and health survey 2014-15. Rockville: Final Report; 2015.

7. Musafili A, Essen B, Baribwira C, Binagwaho A, Persson LA, Selling KE. Trends and social differentials in child mortality in Rwanda 1990-2010: results from three demographic and health surveys. J Epidemiol Community Health. 2015;69(9):834-40 
8. Farmer PE, Nutt CT, Wagner CM, Sekabaraga C, Nuthulaganti T, et al. Reduced premature mortality in Rwanda: lessons from success. BMJ. 2013;346:f65.

9. Mugeni C, Levine AC, Munyaneza RM, Mulindahabi E, Cockrell HC, et al. Nationwide implementation of integrated community case management of childhood illness in Rwanda. Glob Health Sci Pract. 2014;2(3):328-41.

10. Nonyane BAS, Kazmi N, Koffi AK, Begum N, Ahmed S, et al. Factors associated with delay in care-seeking for fatal neonatal illness in the Sylhet district of Bangladesh: results from a verbal and social autopsy study. J Glob Health. 2016:6(1):010605.

11. Bensaid K, Yaroh AG, Kalter HD, Koffi AK, Amouzou A, et al. Verbal/social autopsy in Niger 2012-2013: a new tool for a better understanding of the neonatal and child mortality situation. J Glob Health. 2016;6(1):010602.

12. Nutley T, Reynolds H. Improving the use of health data for health system strengthening. Glob Health Action. 2013;6:20001.

13. Ministry of Health [Rwanda]. National Population Office [Rwanda], and ORC Macro. In: Rwanda Service Provision Assessment Survey 2001. Calverton: Ministry of Health, National Population Office, and ORC Macro; 2003.

14. National Institute of Statistics of Rwanda. The Third Integrated Household Living Conditions Survey (EICV3) In: National Institute of Statistics of Rwanda; 2013

15. World Health Organization. Move it: Report on Monitoring of Vital Events using Information Technology. 2013. http://www.who.int/healthinfo/civil_ registration/crvs_report_it_2013.pdf

16. World Health Organization. Verbal Autopsy Standards: 2012 WHO Verbal Autopsy Instrument. Geneva: World Health Organization; 2012.

17. Byass $P$, Chandramohan D, Clark SJ, et al. Strengthening standardised interpretation of verbal autopsy data: the new InterVA-4 tool. Glob Health Action. 2012;5:10.

18. Rwanda Ministry of Health. Rwanda Annual Health Statistics Booklet 2014. Kigali: Ministry of Health; 2014.

19. GBD 2016 Causes of Death Collaborators. Global, regional, and national agesex specific mortality for 264 causes of death, 1980-2016: a systematic analysis for the Global Burden of Disease Study 2016. Lancet. 2017;390:1151-210.

20. Lawn JE, Blencowe H, Oza S, You D, Lee AC, et al. Every newborn: progress, priorities, and potential beyond survival. Lancet. 2014;384(9938):189-205.

21. Weldearegawi B, Melaku YA, Spigt M, Dinant GJ. Applying the InterVA-4 model to determine causes of death in rural Ethiopia. Glob Health Action. 2014;7:25550.

22. Bhutta ZA, Black RE. Global maternal, newborn, and child health--so near and yet so far. N Engl J Med. 2013;369(23):2226-35

23. Liu L, Li M, Cummings S, Black RE. Deriving causes of child mortality by reanalyzing national verbal autopsy data applying a standardized computer algorithm in Uganda, Rwanda and Ghana. J Glob Health. 2015;5(1):010414.

24. Nahimana E, Ngendahayo M, Magge H, Odhiambo J, Amoroso CL, et al. Bubble CPAP to support preterm infants in rural Rwanda: a retrospective cohort study. BMC Pediatr. 2015;15:135.

25. National Institute of Statistics of Rwanda. Rwanda Poverty Profile Report 2013/14. Kigali: Rwanda Ministry of Health; 2015.

26. Ingabire CM, Rulisa A, Van Kempen L, Muvunyi C, Koenraadt CJ, et al. Factors impeding the acceptability and use of malaria preventive measures: implications for malaria elimination in eastern Rwanda. Malar J. 2015;14:136.

27. Magge H, Anatole M, Cyamatare FR, Mezzacappa C, Nkikabahizi F, et al. Mentoring and quality improvement strengthen integrated management of childhood illness implementation in rural Rwanda. Arch Dis Child. 2015;100(6):565-70.

28. Nankabirwa V, Tumwine JK, Tylleskär T, Nankunda J, Sommerfelt H. The PROMISE EBF research consortium. Perinatal mortality in eastern Uganda: a community based prospective cohort study. PLoS One. 2011;6(5):e19674.

29. Abdullah A, Hort K, Butu Y, Simpson L. Risk factors associated with neonatal deaths: a matched case-control study in Indonesia. Glob Health Action. 2016;9. https://doi.org/10.3402/gha.v9.30445.

30. Moucheraud C, Worku A, Molla M, Finlay JE, Leaning J, Yamin A Consequences of maternal mortality on infant and child survival: a 25-year longitudinal analysis in Butajira Ethiopia (1987-2011). Reprod Health. 2015;12(Suppl 1):S4.

31. Becher $H$, Muller $O$, Jahn A, Gbangou A, Kynast-Wolf G, Kouyate B. Risk factors of infant and child mortality in rural Burkina Faso. Bull World Health Organ. 2004:82(4):265-73.
32. Finlay JE, Moucheraud C, Goshev S, Levira F, Mrema S, et al. The effects of maternal mortality on infant and child survival in rural Tanzania: a cohort study. Matern Child Health J. 2015;19(11):2393-402.

33. Monden CWS, Smits J. Mortality among twins and singletons in subSaharan Africa between 1995 and 2014: a pooled analysis of data from 90 demographic and health surveys in 30 countries. Lancet Glob Health. 2017:5:e673-9.

34. Girma B, Berhane Y. Children who were vaccinated, breast fed and from low parity mothers live longer: a community based case-control study in Jimma, Ethiopia. BMC Public Health. 2011;11:197.

35. Dejene TGE. Social determinants of under-five mortality in Ethiopia. Event history analysis using evidence from Ethiopian demographic and health survey (EDHS). Health. 2013;5(5):879-84.

36. Antai D. Regional inequalities in under-5 mortality in Nigeria: a populationbased analysis of individual- and community-level determinants. Popul Health Metrics. 2011;9:6.

37. Kayode G, Ansah E, Agyepong I, Amoakoh-Coleman M, Grobbee D, Klipstein-Grobusch K. Individual and community determinants of neonatal mortality in Ghana: a multilevel analysis. BMC Pregnancy Childbirth. 2014;14:165.

38. Cleland J, Conde-Agudelo A, Peterson H, Ross J, Tsui A. Contraception and health. Lancet. 2012;380(9837):149-56.

39. McGovern M, Canning D. Vaccination and all-cause child mortality from 1985 to 2011: global evidence from the demographic and health surveys. Am J Epi. 2015;182:9

40. Naz S, Page A, Agho KE. Household air pollution and under-five mortality in India (1992-2006). Environ Health. 2016;15:54.

41. Ezeh OK, Agho KE, Dibley MJ, Hall JJ, Page AN. The effect of solid fuel use on childhood mortality in Nigeria: evidence from the 2013 cross-sectional household survey. Environ Health. 2014;13:113.

42. Van de Poel E, O'Donnell O, Van Doorslaer E. What explains the rural-urban gap in infant mortality: household or community characteristics? Demography. 2009;46(4):827-50.

43. Schoeps A, Souares A, Niamba L, Diboulo E, Kynast-Wolf G, et al. Childhood mortality and its association with household wealth in rural and semi-urban Burkina Faso. Trans R Soc Trop Med Hyg. 2014;108(10):639-47.

44. Binagwaho A, Hartwig R, Ingeri D, Makaka A. Mutual Health Insurance and the Contribution to Improvements in Child Health in Rwanda. Rotterdam: International Institute of Social Studies: Erasmus University; 2012.

45. James C, Morris SS, Keith R, Taylor A. Impact on child mortality of removing user fees: simulation model. BMJ. 2005;331(7519):747-9.

46. Navale S, Habumugisha L, Amoroso C, Sayinzoga F, Gupta N, Hirschhorn L. Understanding drivers of infant deaths in rural Rwanda through verbal social autopsy. Annals of Global Health. 2017:83:756-66.

47. Kalter HD, Salgado R, Babille M, Koffi AK, Black RE. Social autopsy for maternal and child deaths: a comprehensive literature review to examine the concept and the development of the method. Popul Health Metr. 2011;9:45.

48. Leitao J, Chandramohan D, Byass P, Jakob R, Bundhamcharoen K, et al. Revising the WHO verbal autopsy instrument to facilitate routine cause-ofdeath monitoring. Glob Health Action. 2013;6:21518.

49. Rwanda Biomedical Center. National HIV Annu Rep 2014-2015. Kigali: Rwanda Biomedical Center.

\section{Ready to submit your research? Choose BMC and benefit from:}

- fast, convenient online submission

- thorough peer review by experienced researchers in your field

- rapid publication on acceptance

- support for research data, including large and complex data types

- gold Open Access which fosters wider collaboration and increased citations

- maximum visibility for your research: over $100 \mathrm{M}$ website views per year

At $\mathrm{BMC}$, research is always in progress.

Learn more biomedcentral.com/submission 